International Journal of Education (IJE), Vol. 3, No. 3, September 2015

\title{
IMPACT OF BUSINESS INTELLIGENCE ON EMPLOYEE KNOWLEDGESHARING IN JORDANIAN TELECOMMUNICATION COMPANY
}

\author{
${ }^{1}$ Abdel Rahim. M. Zabadi (Corresponding Author), ${ }^{2}$ Mohammad saleem alshura \\ ${ }^{1}$ University of Business \& Technology College of Engineering \& Information \\ Technology \\ ${ }^{2}$ The world Islamic sciences \& Education University College of Business
}

\begin{abstract}
Background: As a result of enormous progress in the information technology and communications, several organizations adopt business intelligence (BI) applications in order to cope with the development in business mechanisms, staying at the marketplace, competition, customer possession and retention.

The rapid growing capabilities of both generating and gathering data has created an imperative necessity for new techniques and tools can intelligently and automatically transform the processed data in to a valuable information and knowledge. Knowledge management is a cornerstone in selecting accurate information at the appropriate time from many relevant resources.
\end{abstract}

Objective: The major Objective of this research is to "examine the impact of business intelligence on employee's knowledge sharing at the Jordanian telecommunications company (JTC)".

Design/methodology/approach: A review of the literature serves as the basis for measuring the impact of business intelligence using knowledge sharing scale. The study sample consisted of administrators, technical staff, and senior managers.75 questionnaires were distributed in the site of JTC. (70) Questionnaires were collected. (63) Found statistically usable for this study representing a response rate of $(84 \%)$.

Findings: Most important findings for this study demonstrate that business intelligence tools respectively (OLAP, Data Warehousing, and Data Mining)are highly effect on employee knowledge sharing.

Originality/Value: Business Intelligence play a significant role in obtaining the underlying knowledge in the organization, through optimum utilization of data sources the internal and external alike. Several researches addressed the importance of integrating business intelligence with knowledge management, little of these researches addressing the impact of business intelligence on knowledge sharing. This study has tried to address this need.

KEY WORDS: Business Intelligence (IB), Data Mining, Data Warehousing, Online Analytical Processing (OLAP), Knowledge Sharing.

Paper type: Research paper

\section{INTRODUCTION}

The tremendous advance in information and communication technology has led to radical change in the way organizations in accomplishing business. The rapid growing capabilities of both generating and gathering data has created an imperative necessity for new techniques and tools

DOI : 10.5121/ije.2015.3306 
International Journal of Education (IJE), Vol. 3, No. 3, September 2015

can intelligently and automatically transform the processed data in to a valuable information and knowledge. Knowledge management is a cornerstone in selecting accurate information at the appropriate time from many relevant resources (Cook \& Cook, 2000).

In today's ever-changing world of business, organizations need to be competitive and innovative in order to provide value to shareholders (Blenkhorn \& Fleisher, 2007). One way organizations can achieve this is to extract the maximum possible value from their internal data assets by using techniques like interactive graphical data analysis, data mining and predictive analytics. These techniques and tools are part of a discipline referred to as business intelligence (Hawking \& Sellitto, 2010).

It has been observed that the society we live in is gradually turning into a knowledge-based society (Cook \& Cook, 2000).In an era of information revolution and the explosion of knowledge, knowledge management plays a crucial role in selecting right information in a timely manner from their different sources, to be processed so that the organization can maximize utility and exploit it better.

For this, business intelligence becomes a major part of the solution by providing the companies with necessary information needed by decision makers to ensure the sustainability as well to build shareholders value. In addition, KM is a fast and efficient way to manage intellectual property( Manujal \& Kalral, 2009).

BI technologies provide historical, current and predictive views of business operations. In this research we will address only the key components of Business Intelligence: data warehousing, data mining, and online analytical processing(OLAP) and how it has been affected on employee knowledge sharing within organization. This is the main objective of research that the researcher seeks to accomplish.

We are desperately needed for the application of business intelligence and use it effectively to create the information and encourage knowledge sharing practices among employees in the organizations. Business intelligence tools, knowledge sharing systems are available to be used and actually benefit form to achieve success and achieving organizational objectives. This study is paper is structured as follows: literature review, methodology, discussion and findings, finally, the study conclusion.

\section{LITERATURE REVIEW}

In this section, we present a review of the contemporary literature along with critical evaluation of the previously presented techniques encompassing BI tools and components Knowledge sharing.

\subsection{Business Intelligence (BI)}

Business Intelligence (BI) becomes essential element in the various business sectors;in particular the information technology (IT)sector. Business Intelligence is not a product, but a framework of concepts, practices, tools, and techniques that help to understand the potential of the company's core and footage from the condition. As well as providing opportunities to create a competitive advantages.

Business Intelligence can be described as a set of comprehensive tools and processes integrated and coherent with each other are used to extract and collect and update and store and analyze data for the purpose of providing information and support offered to take business decisions process. 
$\mathrm{BI}$ is theories and methodology, processes and characteristics and techniques based on the conversion raw data into useful information meaningful for business purposes. And it has the ability to handle huge numbers of information to assist organizations in identifying and developing new business opportunities, and take advantage of new opportunities and implement an effective strategy.

Simply "Business Intelligence" has been defined as: employment of technology in the use of accurate real-time information, with the value of high-quality related to the field of the work itself and data are of great reliability available from several sources, and the application of what has been gained from the experience in order to improve and develop the quality of decisions that must be taken depending on this information.

Business Intelligence is very wide field that includes various types of technologies, comprising among them to create a system characterized by intelligence, serving Business Enterprise to develop the existing capabilities for the application of current strategy and developing them to serve the achievement of goals. Any system consists of basic things must be available, namely:

Data Mining: it's a drilling tools at the data to analyze the results in order derive indirect - or unforeseen relationships.

Data ware housing: development a special security policy for data store and how to access it by duly authorized individuals with specific tasks, So that they are able to analyze and develop new or hidden relationships .OLAP: Building applications in a way that enable to use via Internet browser, this make the user works independently of the operating system. These systems allow companies to gather, store, access, share, and analyze corporate data to help in decision - making. In this research we shall take up combined joint tasks for BI technologies and tools which include: online analytical processing (OLAP), data mining, and data warehousing. In addition, business intelligence includes tools and systems that have a high effect on knowledge management and knowledge sharing activities within organizations. These systems allow companies to gather, store, access, share, and analyze corporate data to help in decision - making. (See Figure 1).

Figure (1): Business Intelligence

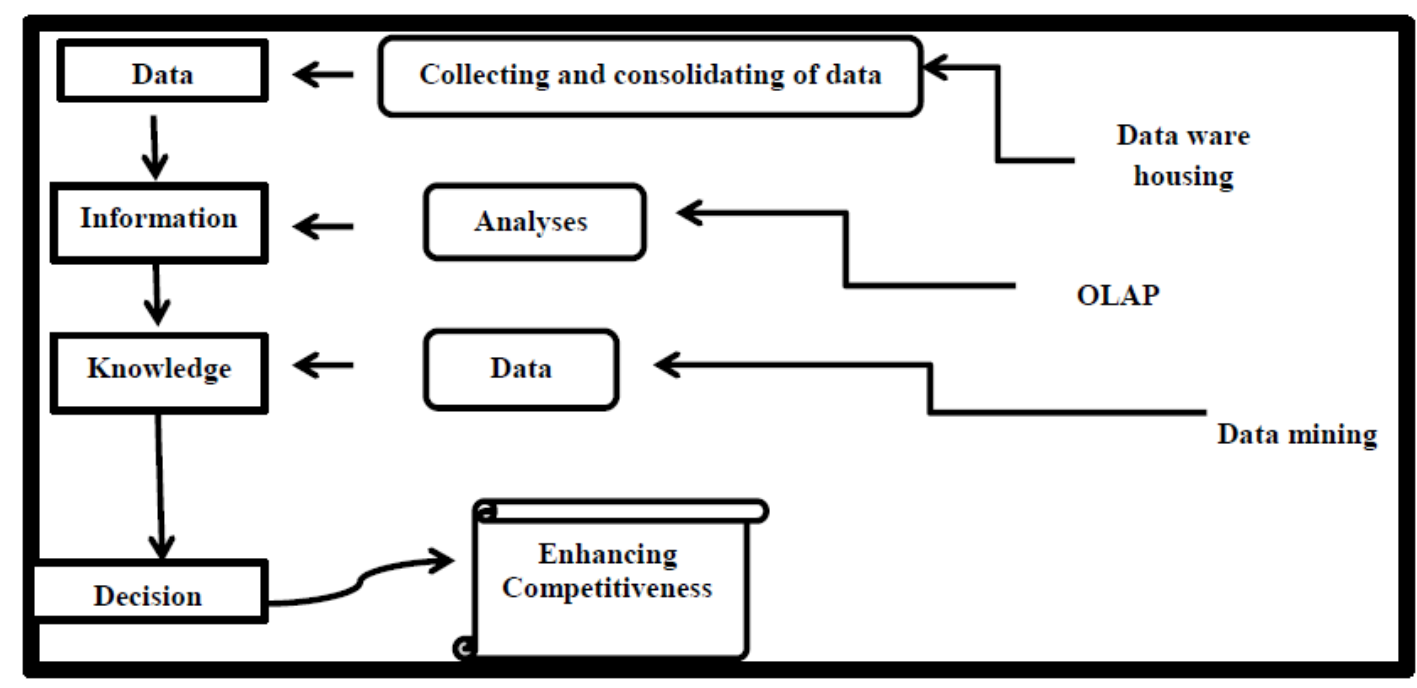


International Journal of Education (IJE), Vol. 3, No. 3, September 2015

\subsection{Business Intelligence Tools}

Business intelligence tools are software tools which allow the retrieval, analysis and reporting of data(Nemati et al, 2002). This includes a wide variety of software tools which are: data mining, data warehousing, and OLAP that help organizations management to generate meaningful knowledge to perform short and long term strategic planning (Malhotra, 2004).

\subsubsection{Data Mining}

Data mining is a process of discovering patterns, correlation and trends by modifying through the large amount of data, which stored in the warehouse. Recognition technologies, statistical and mathematical techniques are normally used in Data Mining technology (Gul Muhammad et al., 2014).

\subsubsection{Data Warehouse}

Data warehouse is the significant component of business intelligence. Data warehouse is an integrated collection of the summarized and historic data, which is collected from internal and external data sources (G.Radonic, 2007). Data warehouse collects relevant data into a repository, where it is organized and validated so it can serve decision - making objectives (Rao \& Kumar,, 2011).

It also includes business definitions, data quality alerts, organizational changes, business rules and assumptions, as well as other items of business interest. Metadata help the business user to understand what is available, how to access it, what it means, which data to use, when to use them, etc. Metadata browsers provide an easy to understand view of the data warehouse (Khan, 2012).

\subsubsection{On - Line Analytical Processing (OLAP)}

OLAP refers to technology that enables the user to interact and present the data in the data warehouse. OLAP is used essentially to query the data warehouse, and the response to these complex queries is recalculated by the software in order to respond to requests (Sabherwal \&Fernandez , 2011).OLAP tools are a combination of analytical processing procedures and graphic user interface. The key features of an OLAP application are multidimensional views of data, calculation intensive capabilities, and time intelligence (Khan, 2012).

\subsection{KNOWLEDGE SHARING}

From the reviewing of the knowledge sharing literature, we found that, there is no comprehensive definition about knowledge sharing. Each scholar has their own perspectives, definitions, explanations of knowledge sharing. Knowledge sharing practices is one of the most important components of knowledge management as it plays a significant role in the company's success and excellence.

(Cook \& Cook, 2000), viewed knowledge sharing as"Business insider has to understand the past result, and share their knowledge with the employees working on that project. (Lin, 2007), for an organization, knowledge sharing is capturing, organizing, and transferring experience-based knowledge that resides within the organization and making that knowledge available to others in the organization.

An organization has realized that knowledge is considered an extremely valuable resource which shall led them to achieving and sustaining competitive advantages. Knowledge sharing activities 
are generally supported by knowledge management systems. However, technology constitutes only one of the many factors that affect the sharing of knowledge in organizations, such as organizational culture, trust, and incentives.

Knowledge Sharing Knowledge sharing is the actual process of sharing knowledge (information, skills, and expertise) explicit or tacit and exchanging it among people, friends, members of a family of organization (Cook and Cook, 2000; Williams and Williams, 2006). An organization has realized that knowledge is considered an extremely valuable resource which shall led them to achieving and sustaining competitive.

Sharing of knowledge constitutes a major challenge in the field of knowledge management because some employees tend to resist sharing their knowledge with the rest of the organization. This requires employing the skills and techniques of knowledge engineers who help employees realize the importance of knowledge sharing within their organizations (Samer et al., 2013).

\section{RESEARCH OBJECTIVES}

This research contributes to our understanding of an increasingly important practical problem, the role of business intelligence in knowledge sharing. In a bid to assess this role, the research specifically aims at:

1) Investigate Business tools at Jordan telecommunications Company.

2) Reveal the positive impact of BI tools in accomplishing knowledge sharing among employees.

3) Find out BI tools influence on Knowledge sharing between employees.

\section{RESEARCH MODEL}

BI tools such as Data mining, Data warehouse, OLAP, and knowledge sharing will be used in this study to test hypotheses. This model consists of two types of variables: the independent variable BI Tools (Data Mining, Data warehouse, and PLAP), and the dependent variable Knowledge sharing, (See Figure 2).

\section{RESEARCH HYPOTHESES}

Based on the findings of prior studies, and according to the research model, as well as to achieve the research objectives, the following null four major can be stated for this study:

Hypothesis 1: BI tools are associated negatively with knowledge sharing at JTC.

Hypothesis 2:There is no statistically significant impact between OLAP knowledge sharing.

Hypothesis 3: There is no statistically significant impact between data mining and knowledge sharing.

Hypothesis 4:There is no statistically significant impact between data warehousing and knowledge sharing. 
Figure (2):RESEARCH MODEL

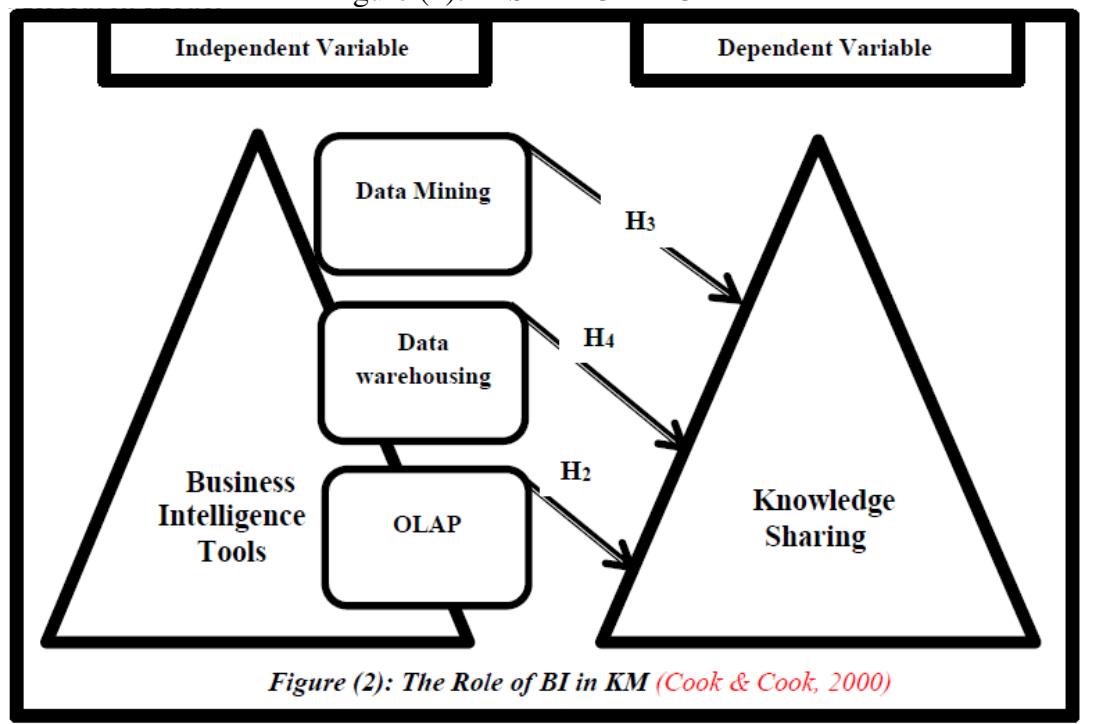

\section{METHODOLOGY AND PROCEDURE}

\section{1: Sample}

In sampling stage, the study based on a convenience sample of (75) employees. 75 questionnaires were distributed to each employee using drop and collect method in the site of (JTC) to answer the questionnaire. The Objective of the study is clear to all participants, and given enough time to fill in the questionnaire.(70) Questionnaires were collected; (7) of those were discarded because they were in complete. (63) Found statistically usable for this study representing a response rate of $(\mathbf{8 4} \%)$. Table (1)illustrates the personal characteristics of the sample under consideration.

\begin{tabular}{|l|l|l|}
\hline Items & Count & Percent (\%) \\
\hline Gender & 30 & \\
Male & 33 & 47.7 \\
Female & & 52.3 \\
\hline$\underline{\text { Age }}$ & 6 & \\
$<25$ & 10 & 9.5 \\
$25-30$ & 19 & 15.9 \\
$31-35$ & 12 & 30.2 \\
$36-40$ & 9 & 19.00 \\
$41-45$ & 7 & 14.3 \\
$>45$ & & 11.1 \\
\hline Education & 9 & \\
Diploma's Degree & 32 & 14.3 \\
Bachelor's Degree & 16 & 50.8 \\
Master's Degree & 6 & 25.4 \\
Doctorate Degree & & 9.5 \\
\hline Years of Experience & 15 & \\
1 -5 years & 20 & 23.9 \\
6 - 10 Years & 23 & 31.7 \\
$11-15$ Years & 5 & 36.5 \\
16 Years and more & $\mathbf{6 3}$ Respondent & $\mathbf{1 0 0} \%$ \\
\hline Total &
\end{tabular}

Table 1: Distribution of the study sample according to demographic variables $(\mathrm{N}=63)$ 


\section{2: DATA RELIABILITY}

BI and knowledge sharing data were first tested for reliability using Corn rash's alpha to assess data reliability, the Corn rash's alpha values for the constructs are summarized in Table 2. As most research method guides treat a value higher than (0.7) acceptable level of internal consistency, and suitable for further analysis, which is generally acceptable in scientific research.

\section{MEASURES}

Only a few organizations have any mechanisms in place to measure the value of BI(Gartz, 2004 ). Thus, measurement is considered an important aspect of BI but at the same time it is considered difficult to carry out in practice.

Business intelligence was measured using the knowledge sharing scale, the items include in this scale were based on Business Intelligence tools of [(McKnight, 2003); Williams, S., Williams, N. (2006)], namely, Online Analytical Processing, Data Mining, Data Warehousing. Knowledge Sharing was measured using the recently developed scale by [(Nemati et al, 2002) ;(Darroch, 2003)].

\section{FINDINGS}

A total of (75) questionnaires were distributed, and (63) of them were returned, data analysis demographics showed that, (47.4\%) of respondents were males, and $\mathbf{5 2 . 6 \%}$ ) were females. Which $(\mathbf{9} .5 \%)$ were aged less than (25)years, $(\mathbf{1 5 . 9 \%})$ were limited between the ages (2530),(30.2\%)were limited between the ages(31-35), (19\%) were limited between the ages (3640),(14.3\%)were limited between the ages(41-45), and the rest(11.1\%) were above (45).

Employees educational levels were respectively (14.3\%) holders of Diploma's Degree, (50.8 \%) holders of Bachelor's Degree, (25.4\%) holders of Master's Degree, and $\mathbf{( 9 . 5 \% )}$ were holders of Doctorate Degree.

Respondents experience in years (23.9\%) possesses (1-5) years 'experience, (31.7\%) possesses (6 - 10) experience, $(\mathbf{3 6 . 5 \%})$ possesses $(11$ - 15) experience, $(\mathbf{7 . 9} \%)$ possesses (16 years or more). Table (1) summarizes the results.

\begin{tabular}{|l|l|}
\hline Variables & Cranach's Alpha \\
\hline Data Mining & 0.77 \\
\hline Data warehousing & 0.82 \\
\hline OLAP & 0.74 \\
\hline Knowledge Sharing & 0.81 \\
\hline
\end{tabular}

Table 2: Cronbach's alpha Values of the constructs 
International Journal of Education (IJE), Vol. 3, No. 3, September 2015

\begin{tabular}{|r|r|r|r|}
\hline Variables & $\mathbf{t}-$ value & $\mathbf{P}-\operatorname{value}(\boldsymbol{\rho})$ & $\operatorname{Beta}(\boldsymbol{\beta})$ \\
\hline Data Mining & 2.963 & 0.0059 & 0.254 \\
\hline Data Warehousing & 3.479 & 0.001 & 0.261 \\
\hline OLAP & 4.187 & 0.000 & 0.274 \\
\hline Knowledge Sharing & 2.35 & 0.039 & 0.214 \\
\hline
\end{tabular}

Table (3): Results of regression analysis

\section{HYPOTHESES TEST}

The first hypothesis: "BI tools are associated negatively with knowledge sharing at JTC". Findings indicate that BI tools are associated positively with employee knowledge sharing practices at JTC. This means that this hypothesis should be rejected.

The second hypothesis: "There is no statistically significant impact between OLAP knowledge sharing". Results indicated that the impact of OLAP on knowledge sharing is significant. The results of the multiple regression shows that OLAP has a [beta (0.274), t-value (4.187), and $p$ value (0.000)].These results demonstrate that this hypothesis should be rejected. Also, the results showed that the employee perceived OLAP as an important factor in knowledge sharing.

The third hypothesis: "There is no statistically significant impact between data mining and knowledge sharing". Regression results [beta $(\mathbf{0 . 2 5 4}), \mathbf{t}$ - value (2.963), and $\mathbf{p}$ - value (0.0059)] show that the impact of data mining on employee knowledge sharing is significant at $(\boldsymbol{\alpha}=$ 0.05)level of significance $(\mathbf{P}=\mathbf{0 . 0 0 5 9})$. This demonstrates that data mining not only encourages employee, but also motivate him to share knowledge with others. A result indicates that there is a positive relation between data mining and employee knowledge sharing. Therefore, the third hypothesis is rejected.

The fourth hypothesis: "There is no statistically significant impact between data warehousing and knowledge sharing". Statistical analysis shows that the impact of data warehousing on employee knowledge sharing is significant at $(\boldsymbol{\alpha} \leq \mathbf{0 . 0 5})$ level of significance. Multiple regression analysis shows that data warehousing has a [beta $(0.261), t$ - value $(3.497)$, and $p=(0.001)]$.

These results demonstrate that the result is rejected. These results indicate that employees of JTC perceived data warehousing as an important factor for employee knowledge sharing. The strength of the effect of BI on employee knowledge sharing has been measured by using the statistical analysis as illustrated in table (3). In general In general we can clarify that the research has achieved the desired objectives. Generally, we can say that that the search has achieved the envisaged objectives.

\section{CONCLUSION}

The final results of this research can be summarized as follows:: Multiple regression analysis show that: OLAP, data mining, and data warehousing are significant BI tools that have a positive impact on knowledge employee's knowledge sharing at JTC. This effective influence of BI on employee Knowledge sharing will open the area to search for another ways to strengthen this practices , and finding ways to measure these activities in the future.

Over all, the results of this research are priceless for Jordanian Organizations that purse to achieve knowledge sharing among its employees as well as business sections within organization. 
International Journal of Education (IJE), Vol. 3, No. 3, September 2015

\section{LIMITATIONS}

The study limited by first ; the data were collected in a convenience sampling at JTC in Amman which may have resulted in sampling biases, majority of respondents were technical staff. Second, a relatively small sample of participants were selected, this limitation makes it difficult to generalize.

\section{FUTURE RESEARCH}

From the research, three key opportunities for future research emerge, including:

- Study more business intelligence tools.

- Measuring the value of BI in businesses in general.

- Finally, research on the integration of BI and Knowledge Management (KM) in organizations.

\section{REFERENCES}

[1] Blenkhorn, D.L. \& Fleisher, C.S., (2007).'Performance Assessment in Competitive Intelligence: An Exploration, Synthesis, and Research Agenda', Journal of Competitive Intelligence and Management 4(2), 4-21.

[2] Cook,C \&Cook,M. (2000). The Convergence of Knowledge Management and Business Intelligence. Newyork, NY,available at:www.brint.com/members/online/20080108/intelligen/: Auerbach publications.

[3] Cui, Z., Damiani, E. and Leida, M. (2007). 'Benefits of Ontologies in Real Time Data Access'. Digital Ecosystems and Technologies Conference, DEST '07, (pp. pp. 392-397).

[4] Darroch, jenny. (2003).developing measures of knowledge management behaviors and practices: journal of knowledge management, 7 (5): 41-54.

[5 Gartz, U. (2004 ). "Enterprise Information Management", in Business Intelligence in the Digital Economy: Opportunities, Limitations and Risks, Raisinghani, M. (Ed.) . Hershey: Idea Group Publishing.

[6] Gul Muhammad, Jamaludin Ibrahim, Zeeshan Bhatti, and Ahmad Waqas, "Business Intelligence as a Knowledge Management Tool in Providing Financial Consultancy Services.” American Journal of Information Systems, vol. 2, no. 2 (2014): 26-32. Doi: 10.12691/ajis-2-2-1.

[7] G.Radonic. (2007). " A Review Of Business Intelligence Approaches To Key Business Factors In Banking". " A Review Of Business Intelligence Approaches T Journal of Knowledg Management Practice, Vol. 8, No. 1, PP. 66 - 71.

[8] Hawking , P . \& Sellitto, C . ( 2010). 'Business Intelligence (BI) Critical Success Factors', 21st Australian Conference on Information Systems. Brisbane, Australia, December 1-3: AIS Electronic Library.

[9] Lin, H. (2007). Knowledge sharing and firm innovation capability: an empirical study. International Journal of Manpower, 28(3/4), 315.

[10] Lionel Dawson, L., Jean - Paul Van Belle, J-P., 2013, 'Critical success factors for business intelligence in the South African financial services sector', SA Journal of Information Management 15(1), Art. \#545, 12 pages. http://dx.doi.org/10.4102/ sajim.v15i1.545

[11] Malhotra, Y. (2004), "Why knowledge management systems fail: enablers and constraints of knowledge management in human enterprise', in Koenig, E. and Srikantaiah, T.K. (Eds), Knowledge Management: Lessons Learned ..., ASIST Monograph Series, Information Today, Medford, NJ, pp. 87-112.

[12] McKnight. (2003). "Bringing data mining to the front line, part 2". DM Review, 13(1), :50.

[13] Mouhib Alnoukari. (2009). " Using Business Intelligence Solutions for achieving organization's strategy: Arab International University case study ".

[14] Nemati, H., Steiger, D., Iyer, L. and Herschel, R. (2002), "Knowledge warehouse: an architectural integration of knowledge management, decision support, artificial intelligence and data warehousing,', Decision Support Systems, Vol. 33, pp. 143-61. 
[15] Montana, J. (2000). The legal system and, knowledge management. The Information Management Journal, PP. 54 - 57.

[16] R.Shehzad and M.Khan, "Integrating Knowledge Management with Business Intelligence Processes for Enhanced Organizational Learning", International Journal of Software Engineering and Its Applications, Vol. 7, No. 2, March 2013, pp.83-91.

[17] R.Khan. (2012). " Business Intelligence: An Integrated Approach". The Business Intelligence Journal (BIJ),Vol. 5, No. 1, PP. 64 - 68.

[18] K.Rao and Kumar. (2011). "Framework To Integrate Business Intelligence And Knowledge Management In Banking Industry". Review of Business and Technology Research, Vol. 4, No. 1, pp. $64-86$.

[19] R.Sabherwal and I.B.Fernandez.(2011). Business Intelligence Practices, Technologies, and Management. USA: John Wiley \& Sons, INC.

[20] Samer Barakat.,Hasan Ali., and Hanadi Al -Zegaier. (2013). The role of business intelligence in knowledge sharing: a Case Studyat Al-Hikma Pharmaceutical Manufacturing Company. European Journal of Business and Management, Vol.5,No.2, PP. 2 - 8 .

[21] Stackowiak, R., Rayman, J. and Greenwald, R. (2007). 'Oracle Data Warehousing and Business Intelligence Solutions'. Indianapolis: Wiley Publishing, Inc.

[22] Tvrdikova,L. (2007). 'Support of Decision Making by Business Intelligence Tools', Computer Information Systems and Industrial Management Applications. CISIM '07. 6th International Conference, pp. 368.

[23] Vina,K\& Solani,M . (2014). The Survey Paper on Importance of Integration of Knowledge Management and Business Intelligence. International Journal of Science and Research, Volume 3 Issue 6, PP. 1789 - 1791.

[24] Williams, S, Williams, N. (2006), the Profit Impact of Business Intelligence, Morgan Kaufmann, San Francisco, CA.

[25] Zeng, L., Xu, L., Shi, Z., Wang, M. and Wu, W. (2007). 'Techniques, process, and enterprise solutions of business intelligence. 2006 IEEE Conference on Systems, Man, and Cybernetics October 8-11, 2006. Taipei, Taiwan: Vol. 6, pp. 4722. 